\title{
Sistemas adesivos: uma revisão da literatura
}

\author{
Adhesive systems: a literature review \\ Sistemas adhesivos: revisión de la literatura
}

Laís Froehlich

ORCID: https://orcid.org/0000-0001-6958-6853 Universidade Estadual do Oeste do Paraná, Brasil E-mail: lais_froehlich@ @otmail.com

Marlon Rosin

ORCID: https://orcid.org/0000-0003-2430-9347 Universidade Estadual do Oeste do Paraná, Brasil E-mail: marlon.rosin@hotmail.com

Nicolas Mazur

ORCID: https://orcid.org/0000-0002-1028-396X Universidade Estadual do Oeste do Paraná, Brasil E-mail: nick_mazur@hotmail.com

Bruna Sampaio Boffo

ORCID: https://orcid.org/ 0000-0002-2808-7000 Universidade Estadual do Oeste do Paraná, Brasil E-mail: bruna.boffo@hotmail.com

Henrique Pezzini de Oliveira

ORCID: https://orcid.org/0000-0001-7401-2889

Universidade Estadual do Oeste do Paraná, Brasil Henrique_hpo@hotmail.com

Carine Zanchin

ORCID: https://orcid.org/0000-0002-8060-5338

Universidade Estadual do Oeste do Paraná, Brasil carizanchin@gmail.com

Tito Pires Terres Neto

ORCID: https://orcid.org/0000-0001-8752-7670

Universidade Estadual do Oeste do Paraná, Brasil

E-mail: terres.tito@gmail.com

Rolando Plümer Pezzini

ORCID: https://orcid.org/0000-0002-3611-2149

Universidade Estadual do Oeste do Paraná, Brasil

E-mail: odontopezzini@gmail.com

Fabiana Scarparo Naufel

ORCID: https://orcid.org/0000-0003-0486-8512

Universidade Estadual do Oeste do Paraná, Brasil

E-mail: biberes@terra.com.br

Eduardo Benassi dos Santos

ORCID: https://orcid.org/0000-0002-7279-5450

Universidade Estadual do Oeste do Paraná, Brasil

E-mail: benassi.odonto@gmail.com

\section{Resumo}

Os sistemas adesivos são responsáveis por promover a união entre o substrato dental e a restauração propriamente dita. Desde Buonocore, estes materiais sofreram importantes transformações. Diante disso, o presente estudo tem por objetivo revisar a literatura sobre as classificações, principais características e ação dos sistemas adesivos atuais. Trata-se de um estudo descritivo qualitativo, realizado através de um levantamento bibliográfico de artigos científicos publicados nos últimos 11 anos. Os sistemas adesivos convencionais são considerados complexos na pratica clínica. Já os autocondicionantes apresentam maior facilidade de aplicação que o anterior e boa adesão quando realizado o condicionamento ácido seletivo do esmalte. Enquanto isso, os adesivos universais apresentam uma composição mais complexa com a mistura de monômeros hidrófilos e hidrofóbicos que promovem adesão química ao dente. Quanto aos adesivos autocondicionantes de etapa única, a dupla aplicação da camada de adesivo pode melhorar a força e a qualidade da adesão. O adesivo universal possui potencial de ligação química como um benefício adicional, que depende de alguns monômeros funcionais. Dentre eles, o mais notável é o 10-metacriloiloxidecil-di-hidrogênio (10MDP ou MDP), um monômero de fosfato que se liga ionicamente à dentina. Os adesivos universais demonstram bons resultados de resistência de união em dentina já condicionada ou não. Sem ataque ácido seletivo, os adesivos autocondicionantes são inferiores aos convencionais, já em esmalte preparado, ambos são equivalentes. Atualmente é 
possivel selecionar o melhor sistema adesivo para cada realidade clínica, atingindo bons resultados mesmo quando se tem limitações de tempo ou de recursos em seu local de trabalho.

Palavras-chave: Adesivos dentinários; Adesividade; Condicionamento ácido do dente.

\begin{abstract}
The adhesive systems are responsible for promoting the union between the dental substrate and the restoration itself. Since Buonocore, these materials have undergone important transformations. Therefore, the present study aims to review the literature on the classifications, main characteristics and action of current adhesive systems. It is a qualitative descriptive study, carried out through a bibliographic survey of scientific articles published in the last 11 years. Conventional adhesive systems are considered complex in clinical practice. The self-etchers, on the other hand, are easier to apply than the previous one and have good adhesion when selective enamel etching is performed. Meanwhile, universal adhesives have a more complex composition with a mixture of hydrophilic and hydrophobic monomers that promote chemical adhesion to the tooth. As for single-stage self-etching adhesives, the double application of the adhesive layer can improve the strength and quality of the adhesion. The universal adhesive has chemical bonding potential as an additional benefit, which depends on some functional monomers. Among them, the most notable is 10-methacryloyloxidecyl-dihydrogen (10-MDP or MDP), a phosphate monomer that binds ionically to dentin. Universal adhesives demonstrate good bond strength results in dentine that is already conditioned or not. Without selective acid attack, self-etching adhesives are inferior to conventional ones, already in prepared enamel, both are equivalent. Currently, it is possible to select the best adhesive system for each clinical reality, achieving good results even when you have time or resource limitations in your workplace.
\end{abstract}

Keywords: Dentin adhesives; Adhesiveness; Acid conditioning of the tooth.

\title{
Resumen
}

Los sistemas adhesivos son los encargados de favorecer la unión entre el sustrato dental y la propia restauración. Desde Buonocore, estos materiales han sufrido importantes transformaciones. Por tanto, el presente estudio tiene como objetivo revisar la literatura sobre las clasificaciones, principales características y acción de los sistemas adhesivos actuales. Se trata de un estudio descriptivo cualitativo, realizado a través de un relevamiento bibliográfico de artículos científicos publicados en los últimos 11 años. Los sistemas adhesivos convencionales se consideran complejos en la práctica clínica. Los autograbadores, en cambio, son más fáciles de aplicar que el anterior y tienen buena adherencia cuando se realiza el grabado selectivo del esmalte. Mientras tanto, los adhesivos universales tienen una composición más compleja con una mezcla de monómeros hidrófilos e hidrófobos que promueven la adhesión química al diente. En cuanto a los adhesivos autograbantes de una sola etapa, la doble aplicación de la capa adhesiva puede mejorar la resistencia y la calidad de la adhesión. El adhesivo universal tiene potencial de unión química como beneficio adicional, que depende de algunos monómeros funcionales. Entre ellos, el más notable es el 10metacriloiloxidocil-dihidrógeno (10-MDP o MDP), un monómero de fosfato que se une iónicamente a la dentina. Los adhesivos universales demuestran buenos resultados de adherencia en dentina ya acondicionada o no. Sin ataque ácido selectivo, los adhesivos autograbantes son inferiores a los convencionales, ya en esmalte preparado, ambos son equivalentes. Actualmente, es posible seleccionar el mejor sistema adhesivo para cada realidad clínica, logrando buenos resultados incluso cuando tienes limitaciones de tiempo o recursos en tu lugar de trabajo.

Palabras clave: Adhesivos de dentina; Viscosidad; Acondicionamiento ácido del diente.

\section{Introdução}

Com a evolução da Odontologia e aprimoramento dos materiais restauradores estéticos, os sistemas adesivos tornaram-se grandes aliados na prática clínica. Esse material é definido como responsável por promover a união entre o substrato dental e a restauração propriamente dita (Moura; \& Araújo, 2019). Atualmente, o sucesso dos tratamentos dentários conservadores centra-se na longevidade desta união (Martins, 2014).

Desde Buonocore no ano de 1955, os sistemas adesivos sofreram importantes transformações. O autor iniciou a era da odontologia minimamente invasiva quando propôs o tratamento com ácido fosfórico 85\% em esmalte para melhorar a retenção da resina acrílica ao tecido (Moura; \& Araújo, 2019). De maneira semelhante, hoje a aplicação prévia por 30 segundos do ácido fosfórico em concentrações de até $40 \%$ sobre a superfície dental melhora o selamento marginal das restaurações em resina composta(Arielli, Pereira, Prado, \& Rabello, 2016).

Ao longo de várias décadas a concepção de adesão ao esmalte permaneceu estável, posto que o esmalte é um substrato uniforme. De maneira oposta, a adesão à dentina apresentou-se imprevisível (Coelho, Canta, Martins, Oliveira, \& Marques, 
2012) levando à modificações na composição química dos materiais, resultando na melhoria das propriedades mecânicas e ópticas destes produtos, bem como variações na aplicação técnica (Moura; \& Araújo, 2019).

Esses sistemas adesivos são classificados em convencionais ou autocondicionantes de acordo com a forma de tratamento da smear layer (Santos \& Mendes, 2018), e mais recentemente surgiram os universais, que podem ser aplicados pelas duas técnicas. Se categorizam também segundo o número de passos clínicos em 1, 2 ou 3 passos e ainda conforme a geração a que pertencem, de $1^{\mathrm{a}}$ a $7^{\mathrm{a}}$ geração (Coelho et al., 2012)

A adesão entre os substratos dentais e o material restaurador é baseada em um processo de troca, alguns mineirais saem do tecido dental dando espaço aos monomeros resinosos. Essa ação subdivide-se em duas etapas: remoção de cálcio e formação de porosidade tanto na dentina como no esmalte; a segunda, esta relacionada a penetração e ativação dos monomeros no interior das porosidades mensionadas anteriormente (Arielli et al., 2016), formando uma camada híbrida eficiente (Santos \& Mendes, 2018). A redução da resistência de união ocorre devido a degradação desta camada, que pode ocorrer pela ação da água (degradação hidrolítica) ou de enzimas da dentina (degradação enzimática) (Martins, 2014).

Segundo Ferreira 2018, é considerado eficiente o adesivo que proporciona uma camada hibrida uniforme e contínua que isola totalmente a polpa do meio externo para não haver sensibilidade pós operatória. $\mathrm{O}$ autor ressalta que esta última pode também ser decorrente da utilização clínica inadequada.

Diante disso, o presente trabalho objetiva revisar a literatura sobre as classificações, principais características e ação dos sistemas adesivos, bem como estratégias que visem a obtenção de melhores resultados, auxiliando na escolha do material mais adequado a necessidade clínica do cirurgião dentista.

\section{Metodologia}

O presente trabalho é caracterizado como um estudo descritivo qualitativo, realizado através de um levantamento bibliográfico de artigos científicos. Sendo reconhecido pela interpretação e opinião formada sobre o tema em questão (Pereira, Shitsuka, Parreira, \& Shitsuka, 2018).

As bases de dados selecionadas foram PubMed e Google Scholar nos últimos 11 anos sendo excluídos artigos anteriores a esse período. As informações foram sintetizadas com intuito de condensar conhecimento sobre a temática. Desse modo, informando de modo prático e breve a comunidade acadêmica sobre as classificações, principais características e ação dos sistemas adesivos, bem como demonstrar estratégias que visem a obtenção de melhores resultados em realçao a adesão, auxiliando assim na escolha do material mais adequado a necessidade clínica do cirurgião dentista.

\section{Resultados e Discussão}

\subsection{Histórico dos sistemas adesivos}

Os materiais de primeira geração surgiram na década de 50 e 60 e nas primeiras três gerações a adesão fundamentouse na modificação da smear layer. Os adesivos basearam-se no uso de grupos ácidos, para reagir com o cálcio, e compostos metacrilatos, para copolimerizar com a resina. No entanto, a interação dos adesivos com a dentina foi superficial e, além disso, era necessário o condicionamento do esmalte com um ácido forte, num passo clínico separado (Coelho et al., 2012). Dado isso, surgiram os adesivos convencionais de 3 passos clínicos, compreendidos por condicionamento ácido, primer e adesivo, dando início a quarta geração (anos 80) (Moura; \& Araújo, 2019), que representou uma mudança na linha de pensamento, utilizandose do ácido fosfórico em esmalte e dentina para remover por completo a smear layer e expor a rede de fibras colágenas (Coelho et al., 2012).

Com o propósito de reduzir o tempo clínico surgiram os adesivos da quinta geração, com aplicação em 2 passos clínicos (condicionamento ácido seguido por primer e adesivo em um único frasco), ainda de adesivos convencionais. Em 
busca de uma adesão menos sensível desenvolveu-se a sexta geração, trazendo os adesivos autocondicionantes de dois passos clínicos, agora contendo primer ácido em um frasco e, em outro, o adesivo. Logo após, surgiu a sétima geração desses materiais, chamados adesivos universais, combinando numa mesma solucão primer ácido e adesivo, possibilitando sua utilização em um único passo clínico (Moura; \& Araújo, 2019).

\subsection{Sistemas adesivos convencionais}

Conhecidos como "etch-and-rinse" (Filho, Fares, Fiuza, Nagem, \& Couto, 2014), os adesivos convencionais baseiamse na desmineralização de esmalte e dentina pela aplicação primeiramente do ácido fosfórico (Lopes et al., 2016), geralmente utilizado na concentração de 37\% (Moura; \& Araújo, 2019). Podendo ser comercializados em sistema de 2 ou 3 passos clínicos (Santos \& Mendes, 2018), os adesivos de três passos consistem na aplicação do ácido e lavagem com água, seguida da aplicação do primer e adesivo, que são aplicados individualmente (Filho et al., 2014), já nos sistemas de dois passos, primer e adesivo estão em um frasco (Arielli et al., 2016). O sistema de três passos geralmente se apresenta com uma seringa e dois frascos, já o de dois passos compõe-se de uma seringa e um frasco (Filho et al., 2014).

No esmalte, o condicionamento ácido gera remoção dos minerais resultando em microporosidades que são preenchidas por monômeros resinosos e hidrofóbicos presentes no adesivo, formando os chamados tags resinosos, essenciais para a retenção micromecânica do material restaurador (Santos \& Mendes, 2018).

De forma diferente, em dentina, a adesão é dificultada não só pela composição mais orgânica desse substrato, mas também pela umidade contida nos túbulos dentinários e pela presença da smear layer - uma camada formada basicamente por bactérias, sangue e saliva provenientes do preparo cavitário, que fica depositada na superfície da dentina e no interior dos túbulos dentinários, onde recebe o nome de smear plug. Esta camada de resíduos reduz a permeabilidade da dentina e o fluxo de fuido dentinário (Arielli et al., 2016).

Deste modo, o ataque com ácido fosfórico em dentina deve promover a remoção completa da lama dentinária seguida da desmineralização deste substrato e consequente exposição das fibras colágenas para que ocorra a hibridização (Lopes et al., 2016).

A dentina condicionada deve ser mantida úmida para que ocorra uma eficiente hibridização do tecido dentinário, pois para a posterior infiltração do agente adesivo é essencial que as fibrilas colágenas expostas se mantenham expandidas pela presença de água, preservando os espaços interfibrilares (Oliveira, Diniz, Svizero, D’Alpino, \& Pegoraro, 2010). O controle da umidade dentinária ainda representa um desafio para clínicos e pesquisadores (Arielli et al., 2016).

Outro problema relacionado aos sistemas adesivos convencionais é a extensão do tempo de aplicação do ácido fosfórico em dentina, que deve ser aplicado somente por 15 segundos, pois um ataque ácido por tempo maior comprometeria a durabilidade da união, pois a desmineralização alcançaria uma profundidade superior do que a penetração dos monômeros, expondo a parte inferior das fibras colágenas. Estas tenderão a sofrer uma lenta hidrólise pela penetração dos fluidos dentinários, contribuindo para o colapso da camada híbrida e enfraquecer a adesão (Oliveira et al., 2010).

Apesar da sensibilidade que a técnica exige, o adesivo convencional de 3 passos foi considerado padrão-ouro para a adesão adequada e se mostrou superior a técnica convencional de 2 passos (Santos \& Mendes, 2018). No entanto, embora com excelentes resultados, alguns clínicos consideram os sistemas adesivos convencionais confusos e complexos de serem utilizados (Lopes et al., 2016)

\subsection{Sistemas adesivos autocondicionantes}

Também chamados "self-etching" (Filho et al., 2014), os sistemas adesivos autocondicionantes foram desenvolvidos na estatégia de diminuir o tempo de trabalho apresentado pelos sistemas adesivos convencionais (Arielli et al., 2016), 
simplificando a técnica de adesão junto à dentina, visto que essa representa um desafio maior se comparada ao esmalte (Valmari Ceris Gaspar Ferreira, 2018). Ficando menos sensível à técnica, ou seja, não demanda tamanha habilidade do operador (Perdigão, Duarte, \& Lopes, 2003).

A principal diferença entre os dois é que o sistema autocondicionante não necessita da aplicação prévia e isolada do ácido fosfórico, uma vez que seu primer já é acídico (Santos \& Mendes, 2018). Dessa forma, ocorre uma desmineralização e simultânea infiltração do adesivo no tecido dentinário, formando a camada híbrida imediata (Lopes et al., 2016). Como não há a remoção total da "smear layer" apresenta menos sensibilidade pós-operatória. Diferentemente dos "total-etch" que podem ter uma infiltração resinosa incompleta até a camada híbrida, os primers "self etch" não apresentam esse problema, pois ambos os processos acontecem de forma simultânea (Perdigão et al., 2003). Consequentemente, há uma redução no tempo de trabalho e no risco da ocorrência de erros durante essa técnica (Arielli et al., 2016).

Os adesivos autocondicionantes podem apresentar dois ou um passo clínico. Os sistemas de dois passos reúnem o agente condicionador e o primer em um mesmo frasco e somente o adesivo é aplicado separadamente; já o de passo único (allin-one) combina ácido, primer e adesivo em um mesmo frasco (Oliveira et al., 2010). Ambos não requerem lavagem (Filho et al., 2014).

A intensidade de interação entre o adesivo autocondicionante com a dentina depende da acidez do primer utilizado (Filho et al., 2014). Sendo assim, estes sistemas podem ser divididos em quatro categorias: ultraleve ( $\mathrm{pH} \geq 2.5$ ), leve ( $\mathrm{pH} \approx 2$ ), intermediária $(\mathrm{pH} \approx 1.5)$ e forte $(\mathrm{pH}<1)$ (Santos \& Mendes, 2018).

A profundidade máxima da desmineralização da dentina conseguida pelos adesivos leves e ultraleves é de apenas 1 micrômetro. No entanto, é suficiente para garantir a hibridização. Isso ocorre devido a composição química dos adesivos, ou seja, o tipo de monômero funcional incluído na sua formulação está relacionado ao sucesso da união, pois alguns, como o 10MDP, possuem potencial de adesão química ao cálcio da hidroxiapatita (presente na composição da dentina), atuando como uma adesão adicional (Arielli et al., 2016).

No entanto, embora os sistemas adesivos autocondicionantes mostram-se eficazes em dentina, apresentam uma adesão ao esmalte significativamente menor se comparada àquela obtida pelo condicionamento com ácido fosfórico (Coelho et al., 2012). Dessa maneira surgiu a técnica de condicionamento ácido seletivo do esmalte, visando melhorar a adesão a este substrato (Lopes et al., 2016). Neste método, realiza-se o condicionamento do esmalte de maneira tradicional com o ácido fosfórico (Santos \& Mendes, 2018) e posterior aplicação do sistema adesivo autocondicionante, tendo assim as vantagens da adesão tradicional do esmalte juntamente com as vantagens obtidas com a técnica autocondicionante aplicada na dentina (Lopes et al., 2016)

Alguns trabalhos mostraram que os adesivos autocondicionantes foram sempre inferiores aos convencionais, sem ataque ácido seletivo. Já em esmalte preparado, ambos foram equivalentes (Coelho et al., 2012). No entanto, outros estudos sobre o condicionamento ácido seletivo do esmalte mostraram que a qualidade da hibridização pode ser diminuída se houver resíduo de ácido fosfórico que foi utilizado no esmalte atingindo a dentina. Procurando solucionar estes problemas surgiram os novos sistemas adesivos chamados Universais (Lopes et al., 2016).

\subsection{Sistemas adesivos universais}

Recentemente, uma nova categoria de adesivo autocondicionante foi introduzida no mercado odontológico como "adesivo universal" (Fujiwara et al., 2018). Recebem este nome por funcionarem tanto como autocondicionantes quanto convencionais, seu modo de apresentação pode ser em dois frascos ou em apenas um, e a técnica de condicionamento ácido seletivo de esmalte pode ser ainda empregada (Santos \& Mendes, 2018), pois sabe-se que este último aumenta significativamente a resistência de união ao esmalte (Lopes et al., 2016). Além disso, os adesivos universais podem também 
ser usados no modo de ataque total com ácido fosfórico sem afetar negativamente a união à dentina (Fujiwara et al., 2018).

Apresentando uma composição mais complexa com a mistura de monômeros hidrófilos e hidrofóbicos (Lorenzetti, Pereira, Kuga, Saad, \& Campos, 2019), adesivos universais demonstram bons resultados de resistência de união em dentina já condicionada ou não, uma vez que os monômeros acídicos presentes na formulação destes adesivos promovem adesão química ao dente (Lopes et al., 2016). No entanto, o pH dos adesivos universais é maior ou igual a 2, o que parece não condicionar apropriadamente o esmalte, por serem menos agressivos que o ácido fosfórico (Arielli et al., 2016). Portanto, para potencializar a ligação micromecânica em esmalte é preciso condicionamento com ácido (Santos \& Mendes, 2018).

\subsection{Estratégias para otimizar a adesão e seus resultados a longo prazo}

A fim de compensar as deficiências dos adesivos autocondicionantes, vêm sendo estudadas e recomendadas algumas abordagens para situações clínicas (Fujiwara et al., 2018), como o controle do campo operatório através do correto isolamento, com o objetivo de evitar a contaminação do substrato preparado com sangue e saliva, o que diminui a força de união. Se esta ocorrer, deverá ser feita a nova hibridização da superfície (Bedran-Russo, Leme-Kraus, Vidal, \& Teixeira, 2017).

Alguns autores sugerem a dupla aplicação da camada de adesivo e concluem que um maior número de camadas pode melhorar a força e a qualidade da adesão dentinária (Filho et al., 2014). Um estudo feito por Fujiwara et al, 2018, para determinar o efeito da aplicação da camada dupla na qualidade de adesão de sistemas adesivos concluiu que além de aumentar a força de adesão inicial, a aplicação dupla foi eficaz em aumentar a durabilidade da união dos adesivos autocondicionantes de etapa única, incluindo adesivos universais. Além disso, é recomendada a polimerização estendida visando melhorar o grau de conversão e reduzir a permeabilidade, utilizando tempos de cura além da recomendação do fabricante (Bedran-Russo et al., 2017).

Outra estratégia que visa melhorias na durabilidade das restaurações diz respeito a utilização de sistemas adesivos que contenham agentes antimicrobianos, como a clorexidina, objetivando a inibição da atividade microbiana, que diminui a degradação da interface estrutura dentária/material restaurador ao longo do tempo. Além de inibir a atividade bacteriana, a clorexidina não interfere ou até melhora as propriedades mecânicas da restauração (Martins, 2014). A aplicação de clorexidina a $2 \%$ antes do condicionamento ácido também apresenta melhoras nas propriedades adesivas (Rayar et al., 2019)

Além disso, outro procedimento que intensifica a adesão e aumenta a força de união entre a superfície dental e o material resinoso é o jateamento com óxido de alumínio $27 \mu$ ou $50 \mu$ após a remoção de cárie e materiais restauradores antigos com brocas e pontas diamantadas e antes do condicionamento ácido (Sinjari et al., 2020).

\section{Considerações Finais}

Os sistemas adesivos evoluíram em vários aspectos desde que Buonocore introduziu o condicionamento com ácido fosfórico. A evolução adesiva caminhou objetivando atingir dois resultados: a excelência em adesão e a simplicidade da técnica. Atualmente é possivel selecionar o melhor sistema adesivo para cada realidade clínica, atingindo bons resultados mesmo quando se tem limitações de tempo ou de recursos em seu local de trabalho. O presente trabalho apresenta as principais informações para auxiliar o cirurgião dentista nessa decisão tão necessária em sua rotina clínica.

\section{Referências}

Arielli, A. M. D., Pereira, K. F., Prado, N. A. S., \& Rabello, T. B. (2016). Sistemas adesivos atuais. Revista Brasileira de Odontologia, 73(3), $242-246$.

Bedran-Russo, A., Leme-Kraus, A. A., Vidal, C. M. P., \& Teixeira, E. C. (2017). An Overview of Dental Adhesive Systems and the Dynamic Tooth-Adhesive Interface. Dental Clinics of North America, 61(4), 713-731. https://doi.org/10.1016/j.cden.2017.06.001

Coelho, A., Canta, J. P., Martins, J. N. R., Oliveira, S. A., \& Marques, P. (2012). Perspetiva histórica e conceitos atuais dos sistemas adesivos 
Research, Society and Development, v. 10, n. 2, e36510212612, 2021 (CC BY 4.0) | ISSN 2525-3409 | DOI: http://dx.doi.org/10.33448/rsd-v10i2.12612

amelodentinários - revisão da literatura. Revista Portuguesa de Estomatologia, Medicina Dentaria e Cirurgia Maxilofacial, 53(1), 39-46. https://doi.org/10.1016/j.rpemd.2011.11.008

Filho, H. N., Fares, H. N., Fiuza, C. T., Nagem, H. D., \& Couto, M. G. P. (2014). Adhesives systems - classification. Full Dent. Sci, 5(20)(December), 655660 .

Fujiwara, S., Takamizawa, T., Barkmeier, W. W., Tsujimoto, A., Imai, A., Watanabe, H., ... Miyazaki, M. (2018). Effect of double-layer application on bond quality of adhesive systems. Journal of the Mechanical Behavior of Biomedical Materials, 77(September 2017), 501-509. https://doi.org/10.1016/j.jmbbm.2017.10.008

Lopes, L. D. S., Malaquias, P., Calazans, F. S., Reis, A., Loguércio, A. D., \& Barceleiro, M. D. O. (2016). Protocolo das pos sibilidades técnicas de aplicação dos sistemas adesivos universais: revisão de literatura com relato de caso. Revistas, 73(2), 173. https://doi.org/10.18363/rbo.v73n2.p.173

Lorenzetti, C. C., Pereira, M. C. da S., Kuga, M. C., Saad, J. R. C., \& Campos, E. A. de. (2019). Influência de tratamento dentinário com EDTA sobre a resistência de união de sistemas adesivos autocondicionantes. Revista de Odontologia Da UNESP, 48, 1-7. https://doi.org/10.1590/1807-2577.00719

Martins, D. O. (2014). “Agentes Antimicrobianos Nos Sistemas Adesivos ".

Moura;, D. A., \& Araújo, L. R. A. (2019). Sistemas Adesivos Contemporâneos: Evolução e Conceitos Atuais. Journal of Chemical Information and Modeling, 53(9), 1689-1699.

Oliveira, N. A. De, Diniz, L. S. M., Svizero, N. da R., D’Alpino, P. H. P., \& Pegoraro, C. A. C. C. (2010). Sistemas adesivos: Conceitos atuais e aplicações clínicas. Revista Dentística on Line, 9(19), 1-9.

Perdigão, J., Duarte, S., \& Lopes, M. M. (2003). Advances in dentin adhesion. Compendium of Continuing Education in Dentistry (Jamesburg, N.J. : 1995), 24(8 Suppl).

Pereira, A. S., Shitsuka, Dorlivete Moreira Parreira, F. J., \& Shitsuka, R. (2018). Metodologia da Pesquisa Científica - Licenciatura em Computação. https://repositorio.ufsm.br/bitstream/handle/1/15824/Lic_Computacao_Metodologia-Pesquisa-Cientifica.pdf?sequence=1 .

Rayar, S., Sadasiva, K., Singh, P., Thomas, P., Senthilkumar, K., \& Jayasimharaj, U. (2019). Effect of 2\% chlorhexidine on resin bond strength and mode of failure using two different adhesives on dentin: An in vitro study. Journal of Pharmacy and Bioallied Sciences, 11(6), S325-S330. https://doi.org/10.4103/JPBS.JPBS_23_19

Santos, A. C. R. dos, \& Mendes, T. O. (2018). Sistemas Adesivos Resinosos: Uma Revisão De Literatura. Interciencia, 489(20), $313-335$.

Sinjari, B., Santilli, M., D’Addazio, G., Rexhepi, I., Gigante, A., Caputi, S., \& Traini, T. (2020). Influence of dentine pre-treatment by sandblasting with aluminum oxide in adhesive restorations. An in vitro study. Materials, 13(13). https://doi.org/10.3390/ma13133026

Valmari Ceris Gaspar Ferreira. (2018). Sistemas Adesivos Autocondicionantes. 1-27. 